\title{
Pengaruh Aktivitas Pemasaran Media Sosial Terhadap Loyalitas Merek: Kesadaran Merek Dan Citra Merek Sebagai Mediasi
}

\author{
Berta Margareta Agustin Wijaya ${ }^{1}$, dan Sheellyana Junaedi ${ }^{2}$ \\ Universitas Atma Jaya Yogyakarta ${ }^{1,2}$ \\ \{bertamargareta886@gmail.com ${ }^{1}$, sheellyana.junaedi@uajy.ac.id $\left.{ }^{2}\right\}$
}

\begin{abstract}
Abstrak: Penelitian ini memiliki tujuan untuk menganalisis pengaruh aktivitas pemasaran media sosial terhadap loyalitas merek, dengan kesadaran merek dan citra merek sebagai mediasi. Penelitian ini menggunakan objek penelitian merek dalam negeri yaitu Scarlett pada media sosial Instagram. Bentuk penelitian ini adalah kuantitatif. Pengumpulan data dilakukan dengan menyebarkan kuesioner. Penelitian ini dilakukan pada 238 responden dengan kriteria pernah membeli produk merek Scarlett minimal 2 kali dalam 1 tahun terakhir, usia minimal 17 tahun, dan mengikuti akun Instagram Scarlett. Penelitian ini bersifat tidak acak yaitu purposive sampling. Pembagian kuesioner dilakukan dengan cara online, yaitu kuesioner dibuat dengan menggunakan aplikasi Google Forms. Lalu, link kuesioner disebarkan secara online melalui berbagai media sosial seperti Whatsapp, Line, Instagram, Twitter, dan Facebook. Analisis data dilakukan menggunakan Structural Equation Modeling (SEM), dengan bantuan software Partial Least Square (PLS). Hasil analisis diketahui bahwa kesadaran merek memediasi aktivitas pemasaran media sosial pada faktor hiburan, faktor iklan, dan faktor trendiness terhadap loyalitas merek. Kemudian, citra merek memediasi aktivitas pemasaran media sosial pada faktor interaksi, dan faktor trendiness terhadap loyalitas merek di Instagram. Sedangkan, kesadaran merek tidak memediasi aktivitas pemasaran media sosial pada faktor interaksi, dan kustomisasi terhadap loyalitas merek. Lalu, citra merek tidak memediasi aktivitas pemasaran media sosial pada faktor hiburan, faktor iklan, dan faktor kustomisasi terhadap loyalitas merek di Instagram.
\end{abstract}

Kata kunci: Aktivitas Pemasaran Media Sosial, Kesadaran Merek, Citra Merek, Loyalitas Merek, Instagram.

Media sosial saat ini banyak digunakan oleh pengusaha baik pengusaha besar maupun kecil. Sesuai dengan pendapat Bilgin (2018) media sosial membuat bisnis menjadi lebih interaktif dalam komunikasi pemasaran dan untuk menemukan aplikasi inovatif untuk membuat produk dan merek lebih terjangkau melalui upaya pemasaran online melalui saluran komunikasi media sosial. Penelitian Sehar, et al.,(2019) menyatakan bahwa media sosial meningkatkan kesadaran di antara konsumen dan menciptakan citra merek. Konstruksi identitas berbanding lurus dengan komunikasi antara merek dan konsumen (Bilgin, 2018). Sesuai dengan menurut Almohaimmeed (2019) adanya efek positif dari pemasaran media sosial pada konstruksi seperti loyalitas merek. Pada penelitian kali ini peneliti memilih media sosial Instagram. Penelitian Ceyhan (2019) menyatakan bahwa Instagram yaitu jejaring sosial dengan konten visual, mencapai 1 juta pengguna sekitar dua bulan setelah diluncurkan oleh App Store pada 2010. Pengguna media sosial berinteraksi dengan merek di Instagram 58 kali lebih banyak daripada di Facebook dan 120 kali lebih banyak daripada di Twitter. Pratnyawan (2019) menyatakan seiring berkembangnya dunia digital, Instagram terus melakukan terobosan-terobosan dalam hal jejaringan sosial berbasis foto 
dan video. Indonesia menjadi posisi ke-4 di dunia dengan total pengguna 56 juta atau 20.97 persen dari total populasi. Di Indonesia, pengguna instagram terbanyak berasal dari rentang usia 18 tahun hingga 24 tahun untuk pria dan wanita. Studi juga mengungkap di awal tahun 2019 ratarata jumlah pengguna instagram laki-laki 1.9 persen lebih banyak dibanding perempuan. Pemerintah menyediakan BEKRAF (Badan Ekonomi Kreatif) bertujuan untuk meningkatkan merek asal Indonesia di mata dunia. BEKRAF juga terus mendorong agar semakin banyak label dalam negeri mengambil ruang di platform e-commerce (Munaf, 2018). (Huda, 2020) Co-founder kosmetik lokal Rollover Reaction, Dinar Amanda menyatakan kemajuan teknologi, media sosial, dan platform digital akan membuat produk kosmetik semakin beragam dan memiliki akses terjangkau bagi konsumen dalam negeri seperti pada Gambar 1. menunjukkan bahwa tiap tahunnya industri kosmetik nasional meningkat baik secara offline dan online.

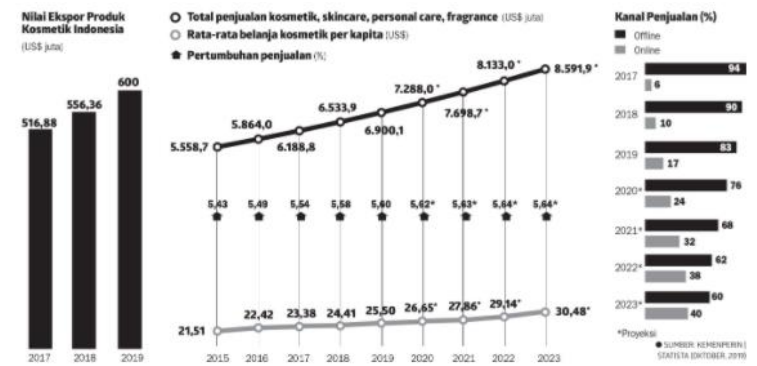

Gambar 1. Perkembangan Industri Kosmetik di Indonesia Sumber: Kementrian Perindustrian Statistik (2019) dikutip Huda (2020)

Hingga tahun lalu, pemerintah mencatat ada 797 industri kosmetik besar dan industri kecil dan menengah (IKM) di Indonesia. Angka ini naik dari 760 perusahaan pada tahun sebelumnya. Dari 797 industri kosmetik nasional. terdapat 294 industri terdaftar di Badan Koordinasi Penanaman Modal (BKPM). Salah satu merek dalam negeri yang cukup menarik perhatian masyarakat adalah Scarlett. Scarlett mengawali penjualan produk dengan menggunakan berbagai features Instagram pada Oktober 2017. Scarlett merupakan merek produk kecantikkan yang dimiliki oleh salah satu actress Indonesia yaitu Felicya Angelista. Scarlett terdaftar pada Badan Pengawasan Obat dan Makanan (BPOM) yang dapat menjamin keamanan dari produk merek tersebut. Scarlett memasang harga pada seluruh produknya sama yaitu 75.000 rupiah. Scarlett memiliki pengikut pada akun Instagram sebanyak 2,3 juta (dikutip dari akun instagram @Scarlett_Whitening). Jumlah pengikut pada akun Instagram Scarlett mampu bersaing dengan merek lokal Wardah (2,7 juta) yang sudah menjadi merek global bahkan melebihi merek lainnya seperti Pixy (411 ribu), Viva (110 ribu), dan Emina (955 ribu) (Akun Instagram Scarlett, Pixy, Viva, Emina, Wardah pada 20 Agustus 2020). Penelitian kali ini memiliki tujuan yaitu menganalisis pengaruh aktivitas pemasaran media sosial terhadap loyalitas merek Scarlett dengan kesadaran merek, dan citra merek sebagai mediasi di Instagram. Hipotesis sebagai berikut: 
H1a-e dan H2a-e: Aktivitas Pemasaran Media Sosial (Hiburan, Interaksi, Trendiness, Iklan, Kustomisasi) Berpengaruh terhadap Kesadaran Merek dan Citra Merek di Media Sosial (Instagram)

H3a-e: Aktivitas Pemasaran Media Sosial (Hiburan, Interaksi, Trendiness, Iklan, Kustomisasi) Berpengaruh terhadap Loyalitas Merek di Media Sosial (Instagram)

H4: Kesadaran Merek Berpengaruh terhadap Citra Merek di Media Sosial (Instagram)

H5-H6: Kesadaran Merek dan Citra Merek Berpengaruh terhadap Loyalitas Merek di Media Sosial (Instagram)

H7a-e dan H8a-e: Aktivitas Pemasaran Media Sosial (Hiburan, Interaksi, Trendiness, Iklan, Kustomisasi) Berpengaruh terhadap Loyalitas Merek dengan Kesadaran Merek dan Citra Merek sebagai Mediasi di Media Sosial (Instagram)

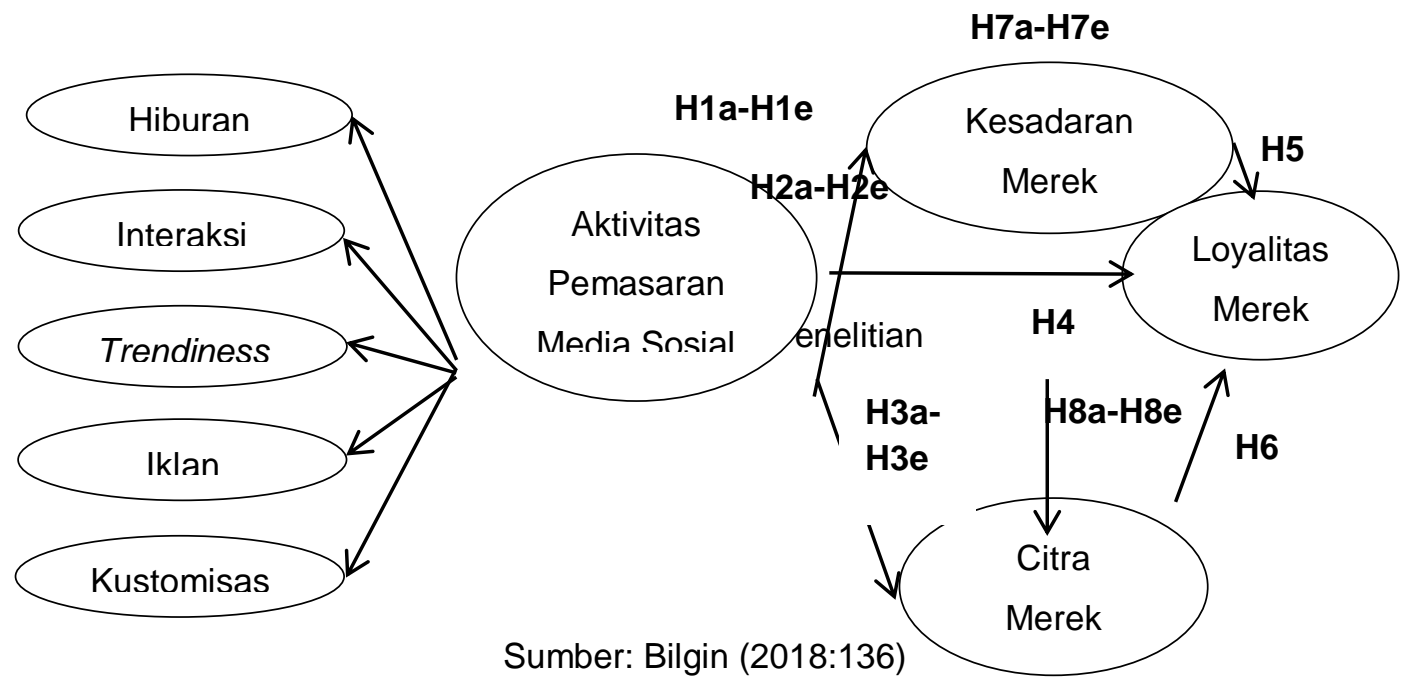

\section{METODE}

Penelitian menggunakan metode kuantitatif sesuai dengan penelitian sebelumnya (Bilgin, 2018). Penentuan sampel dilakukan yaitu purposive sampling yaitu orang yang membeli produk merek Scarlett minimal 2 kali dalam 1 tahun terakhir dengan usia minimal 17 tahun, dan mengikuti akun Instagram Scarlett. Pembagian kuesioner dilakukan dengan cara online membagikan link kuesioner dengan menggunakan aplikasi Google Forms. Metode \& Alat analisis Data Statistik menggunakan Structural Equation Modeling (SEM) dengan Partial Least Square (PLS) sesuai dengan kriteria pada Ghozali, dan Latan (2015), dan menguji efek mediasi menurut Zhao et al., (2010). 
Tabel 2. Demografi Responden ( $\mathrm{n}=238$ responden)

\begin{tabular}{|c|c|c|c|c|}
\hline No. & Demografi & Karakteristik & Jumlah & Presentase \\
\hline \multirow{4}{*}{1} & \multirow{4}{*}{$\begin{array}{c}\text { Berapa kali anda pernah membeli } \\
\text { produk Scarlett dalam } 1 \text { tahun } \\
\text { terakhir? }\end{array}$} & $\begin{array}{l}1 \text { kali (berhenti di } \\
\text { sini) }\end{array}$ & - & - \\
\hline & & 2 kali - 4 kali & 210 & $88,24 \%$ \\
\hline & & 5 kali - 6 kali & 19 & $7,98 \%$ \\
\hline & & $>6$ kali & 9 & $3,78 \%$ \\
\hline \multirow{7}{*}{2} & \multirow{7}{*}{$\begin{array}{l}\text { Produk apa saja yang pernah anda } \\
\text { beli? (boleh lebih dari 1) }\end{array}$} & Body Lotion & 198 & $83,19 \%$ \\
\hline & & Shampoo & 43 & $18,07 \%$ \\
\hline & & Conditioner & 26 & $10,92 \%$ \\
\hline & & Face Serum & 91 & $38,24 \%$ \\
\hline & & Body Scrub & 85 & $35,71 \%$ \\
\hline & & Body Soap & 114 & $47,90 \%$ \\
\hline & & Facial Wash & 61 & $25,63 \%$ \\
\hline \multirow{2}{*}{3} & \multirow{2}{*}{ Jenis kelamin } & Laki - laki & 23 & $9,66 \%$ \\
\hline & & Perempuan & 215 & $90,34 \%$ \\
\hline \multirow{4}{*}{4} & \multirow{4}{*}{ Usia (Tahun). ex: 23} & $17-21$ & 29 & $12,18 \%$ \\
\hline & & $22-26$ & 169 & $65,50 \%$ \\
\hline & & $27-31$ & 32 & $13,45 \%$ \\
\hline & & $>32$ & 8 & $3,36 \%$ \\
\hline \multirow{3}{*}{5} & \multirow{3}{*}{ Pendidikan Terakhir } & SLTA/Sederajat & 45 & $18,91 \%$ \\
\hline & & S1/Diploma & 183 & $76,89 \%$ \\
\hline & & S2/S3 & 10 & $4,20 \%$ \\
\hline 6 & Pendapatan per bulan & $<$ Rp. 1.500 .000 & 55 & $23,11 \%$ \\
\hline \multirow{4}{*}{6} & \multirow{4}{*}{ Pendapatan per bulan } & $\begin{array}{l}\text { Rp. } 1.500 .000- \\
\text { Rp.2.500.000 }\end{array}$ & 80 & $33,61 \%$ \\
\hline & & $\begin{array}{l}\text { Rp. 2.500.001 - } \\
\text { Rp.3.500.000 }\end{array}$ & 35 & $14,71 \%$ \\
\hline & & $\begin{array}{l}\text { Rp. } 3.500 .001- \\
\text { Rp.4.500.000 }\end{array}$ & 27 & $11,34 \%$ \\
\hline & & $>$ Rp. 4.500 .000 & 41 & $17,23 \%$ \\
\hline
\end{tabular}

Sumber : Hasil Olah Data SEM-PLS (2020)

Tabel 3. Hasil Validitas Konvergen dan Reliabilitas

\begin{tabular}{|c|c|c|c|c|c|c|}
\hline No & Konstruk & Indikator & Loading Factor & AVE & Cronbachs a & CR \\
\hline \multirow{3}{*}{1} & \multirow{3}{*}{ Faktor Hiburan } & $\mathrm{X} 1 . \mathrm{FH} 1$ & 0,876 & \multirow{3}{*}{0,687} & \multirow{3}{*}{0,772} & \multirow{3}{*}{0,868} \\
\hline & & $\mathrm{X} 1 . \mathrm{FH} 2$ & 0,783 & & & \\
\hline & & $\mathrm{X} 1 . \mathrm{FH} 3$ & 0,824 & & & \\
\hline \multirow{3}{*}{2} & \multirow{3}{*}{$\begin{array}{l}\text { Faktor } \\
\text { Interaksi }\end{array}$} & X1.FINT1 & 0,868 & \multirow{3}{*}{0,724} & \multirow{3}{*}{0,809} & \multirow{3}{*}{0,887} \\
\hline & & X1.FINT2 & 0,865 & & & \\
\hline & & X1.FINT3 & 0,819 & & & \\
\hline \multirow{2}{*}{3} & \multirow{2}{*}{$\begin{array}{l}\text { Faktor } \\
\text { Trendiness }\end{array}$} & X1.FT1 & 0,893 & \multirow{2}{*}{0,814} & \multirow{2}{*}{0,772} & \multirow{2}{*}{0,897} \\
\hline & & X1.FT2 & 0,911 & & & \\
\hline \multirow{3}{*}{4} & \multirow{3}{*}{ Faktor Iklan } & X1.FIKL1 & 0,847 & \multirow{3}{*}{0,729} & \multirow{3}{*}{0,814} & \multirow{3}{*}{0,890} \\
\hline & & X1.FIKL2 & 0,870 & & & \\
\hline & & X1.FIKL3 & 0,844 & & & \\
\hline \multirow{3}{*}{5} & \multirow{3}{*}{$\begin{array}{l}\text { Faktor } \\
\text { Kustomisasi }\end{array}$} & X1.FK1 & 0,889 & \multirow{3}{*}{0,757} & \multirow{3}{*}{0,840} & \multirow{3}{*}{0,903} \\
\hline & & X1.FK2 & 0,849 & & & \\
\hline & & X1.FK3 & 0,872 & & & \\
\hline \multirow{3}{*}{6} & \multirow{3}{*}{$\begin{array}{l}\text { Kesadaran } \\
\text { Merek }\end{array}$} & Y1.KM1 & 0,884 & \multirow{3}{*}{0,739} & \multirow{3}{*}{0,823} & \multirow{3}{*}{0,894} \\
\hline & & Y1.KM2 & 0,819 & & & \\
\hline & & Y1.KM3 & 0,874 & & & \\
\hline
\end{tabular}




\begin{tabular}{|c|c|c|c|c|c|c|}
\hline \multirow{3}{*}{7} & \multirow{3}{*}{ Citra Merek } & Y2.CM1 & 0,792 & \multirow{3}{*}{0,645} & \multirow{3}{*}{0,724} & \multirow{3}{*}{0,845} \\
\hline & & Y2.CM2 & 0,799 & & & \\
\hline & & Y2.CM3 & 0,818 & & & \\
\hline \multirow{3}{*}{8} & \multirow{3}{*}{$\begin{array}{l}\text { Loyalitas } \\
\text { Merek }\end{array}$} & Z.LM1 & 0,857 & \multirow{3}{*}{0,703} & \multirow{3}{*}{0,788} & \multirow{3}{*}{0,876} \\
\hline & & Z.LM2 & 0,811 & & & \\
\hline & & Z.LM3 & 0,847 & & & \\
\hline
\end{tabular}

Sumber : Hasil Olah Data SEM-PLS (2020)

Berdasarkan Tabel 3. ditemukan bahwa seluruh nilai dari outer loading / loading factors untuk tiap indikator konstruk $\geq 0,70$. Kemudian nilai Average Variance Extracted (AVE) setiap konstruk $\geq 0,50$. Nilai dari Cronbach's alpha $\geq 0,70$ pada tiap konstruk dapat dikatakan reliabel. Kemudian nilai Composite Reliability pada setiap nilai konstruk bila $\geq 0,60$ $\geq 0,70$ dapat dikatakan reliabel. Berarti konstruk pada kuesioner penelitian adalah valid dan reliable (Ghozali dan Latan, 2015).

Tabel 4. Hasil Validitas Diskriminan

\begin{tabular}{|l|c|c|c|c|c|c|c|c|}
\hline & CM & FH & FIKL & FINT & FK & FT & KM & LM \\
\hline CM & 0,803 & & & & & & & \\
\hline FH & 0,792 & 0,829 & & & & & & \\
\hline FIKL & 0,802 & 0,805 & 0,854 & & & & & \\
\hline FINT & 0,784 & 0,833 & 0,773 & 0,851 & & & & \\
\hline FK & 0,793 & 0,810 & 0,854 & 0,780 & 0,870 & & & \\
\hline FT & 0,715 & 0,721 & 0,686 & 0,747 & 0,700 & 0,902 & & \\
\hline KM & 0,828 & 0,821 & 0,846 & 0,768 & 0,810 & 0,710 & 0,860 & \\
\hline LM & 0,814 & 0,802 & 0,795 & 0,778 & 0,787 & 0,700 & 0,825 & 0,838 \\
\hline
\end{tabular}

Sumber : Hasil Olah Data SEM-PLS (2020)

Berdasarkan data pada Tabel 4. ditemukan bahwa nilai FornellLarcker Criterion $\geq 0,70$ pada setiap variable. Kemudian nilai setiap konstruk laten dengan nilai korelasi antar konstruk dalam model lebih besar dari nilai korelasi antar konstruksi laten lainnya. Berarti konstruk pada kuesioner penelitian adalah valid.

\section{HASIL}

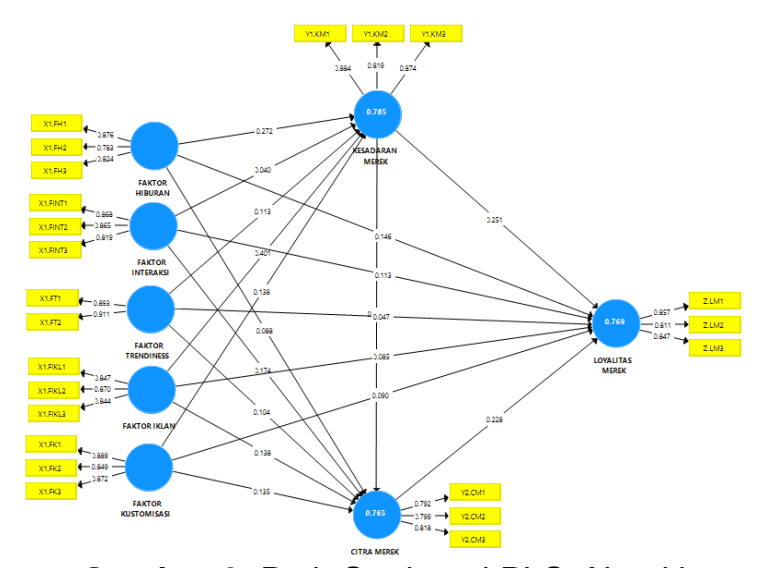

Gambar 3. Path Struktural PLS Algorithm

Sumber : Hasil Olah Data SEM-PLS (2020) 
Tabel 5. Nilai R Square

\begin{tabular}{|l|c|c|}
\hline & R Square & R Square Adjusted \\
\hline CITRA MEREK & 0,765 & 0,759 \\
\hline KESADARAN MEREK & 0,785 & 0,780 \\
\hline LOYALITAS MEREK & 0,769 & 0,762 \\
\hline
\end{tabular}

Sumber : Hasil Olah Data SEM-PLS (2020)

Berdasarkan mengevaluasi model struktural diawali dengan cara melihat $R^{2}$ perubahan nilai R-squares $\left(R^{2}\right)$ dapat digunakan untuk menjelaskan pengaruh variabel laten eksogen tertentu terhadap variabel laten endogen. Kriteria nilai terdiri dari tiga klasifikasi, yaitu: nilai ( \pm ) 0,19 , ( \pm ) 0.33 dan ( \pm ) 0.67 yang mana menunjukkan model lemah, moderate dan kuat (Ghozali \& Latan, 2015). Tabel 5. menunjukkan nilai $R^{2}$ pada ketiga variabel $>0,67$ berarti memiliki pengaruh variabel laten eksogen terhadap variabel laten endogen yang kuat.

Tabel 6. Hubungan Langsung

\begin{tabular}{|c|c|c|c|c|}
\hline & Path Coefficient & T Statistics & P Values & Verification \\
\hline $\mathrm{FH}->\mathrm{KM}$ & 0,272 & $3,701^{*}$ & $0,000^{*}$ & Signifikan \\
\hline $\mathrm{FH} \rightarrow \mathrm{CM}$ & 0,088 & 1,122 & 0,262 & Tidak Signifikan \\
\hline $\mathrm{FH}->\mathrm{LM}$ & 0,146 & $2,175^{\star}$ & $0,030^{*}$ & Signifikan \\
\hline FINT $->\mathrm{KM}$ & 0,040 & 0,594 & 0,553 & Tidak Signifikan \\
\hline FINT $->$ CM & 0,174 & $2,494^{\star}$ & $0,013^{*}$ & Signifikan \\
\hline FINT $->$ LM & 0,113 & $1,709^{\star *}$ & $0,088^{\star \star}$ & Signifikan \\
\hline FT $->\mathrm{KM}$ & 0,113 & $2,056^{*}$ & $0,040^{*}$ & Signifikan \\
\hline FT $>$ CM & 0,104 & $2,056^{*}$ & $0,040^{*}$ & Signifikan \\
\hline FT $\rightarrow$ LM & 0,047 & 0,878 & 0,380 & Tidak Signifikan \\
\hline FIKL -> KM & 0,401 & $5,423^{*}$ & $0,000^{*}$ & Signifikan \\
\hline FIKL $\rightarrow C M$ & 0,138 & 1,642 & 0,101 & Tidak Signifikan \\
\hline FIKL $>$ LM & 0,085 & 1,369 & 0,171 & Tidak Signifikan \\
\hline FK $->\mathrm{KM}$ & 0,138 & 1,598 & 0,110 & Tidak Signifikan \\
\hline FK $->\mathrm{CM}$ & 0,135 & 1,472 & 0,141 & Tidak Signifikan \\
\hline FK $->$ LM & 0,090 & 1,092 & 0,275 & Tidak Signifikan \\
\hline $\mathrm{KM}->\mathrm{CM}$ & 0,322 & $4,123^{*}$ & $0,000^{*}$ & Signifikan \\
\hline KM $\rightarrow$ LM & 0,251 & $3,441^{*}$ & $0,001^{*}$ & Signifikan \\
\hline CM $\rightarrow$ LM & 0,228 & $3,425^{\star}$ & $0,001^{*}$ & Signifikan \\
\hline
\end{tabular}

Keterangan: t-statistik $\geq 1,96^{*} \geq 1,65^{\star *}$ signifikan

Sumber : Hasil Olah Data SEM-PLS (2020)

Berdasarkan hasil pada Tabel 6. ditemukan bahwa Hipotesis 1 (H1a, H1c, H1d diterima dan H1b, H1e ditolak), Hipotesis 2 (H2b, H2c diterima dan $\mathrm{H} 2 \mathrm{a}, \mathrm{H} 2 \mathrm{~d}, \mathrm{H} 1 \mathrm{e}$ ditolak), Hipotesis 3 ( $\mathrm{H} 3 \mathrm{a}, \mathrm{H} 3 \mathrm{~b}$ diterima dan $\mathrm{H3c}, \mathrm{H} 3 \mathrm{~d}, \mathrm{H} 3 \mathrm{e}$ ditolak), Hipotesis 4, 5 dan 6 diterima.

Tabel 7. Hubungan Tidak Langsung

\begin{tabular}{|c|c|c|c|c|}
\hline & Path Coefficient & T Statistics & P Values & Verification \\
\hline FH $>$ KM $>$ LM & 0,068 & $2,696^{*}$ & $0,007^{*}$ & Signifikan \\
\hline FINT $>$ KM $>$ LM & 0,010 & 0,558 & 0,577 & Tidak Signifikan \\
\hline FT $>$ KM $->$ LM & 0,028 & $1,749^{* *}$ & $0,081^{* *}$ & Signifikan \\
\hline FIKL $>$ KM $>$ LM & 0,100 & $3,036^{*}$ & $0,002^{*}$ & Signifikan \\
\hline FK $>$ KM $>$ LM & 0,035 & 1,395 & 0,163 & Tidak Signifikan \\
\hline FH $>$ CM $>$ LM & 0,020 & 1,010 & 0,313 & Tidak Signifikan \\
\hline FINT $>$ CM $>$ LM & 0,040 & $1,985^{*}$ & $0,047^{*}$ & Signifikan \\
\hline
\end{tabular}




\begin{tabular}{|c|c|c|c|c|}
\hline & Path Coefficient & T Statistics & P Values & Verification \\
\hline $\mathrm{FH} \rightarrow>\mathrm{KM} \rightarrow \mathrm{LM}$ & 0,068 & $2,696^{*}$ & $0,007^{\star}$ & Signifikan \\
\hline FINT $->$ KM $\rightarrow$ LM & 0,010 & 0,558 & 0,577 & Tidak Signifikan \\
\hline FT $->$ KM $->$ LM & 0,028 & $1,749^{* *}$ & $0,081^{\star *}$ & Signifikan \\
\hline FIKL $>$ KM $\rightarrow$ LM & 0,100 & $3,036^{*}$ & $0,002^{*}$ & Signifikan \\
\hline FK $->$ KM $->$ LM & 0,035 & 1,395 & 0,163 & Tidak Signifikan \\
\hline FT $->\mathrm{CM} \rightarrow>$ LM & 0,024 & $1,799^{* *}$ & $0,072^{\star \star}$ & Signifikan \\
\hline FIKL $->C M->L M$ & 0,032 & 1,517 & 0,130 & Tidak Signifikan \\
\hline$F K->K M->L M$ & 0,035 & 1,395 & 0,163 & Tidak Signifikan \\
\hline
\end{tabular}

Sumber : Hasil Olah Data SEM-PLS (2020)

Berdasarkan hasil penelitian pada Tabel 7. ditemukan bahwa Hipotesis 7 (H7a, H7c, H7d diterima dan H7b dan H7e ditolak), dan Hipotesis 8 (H8b, H8c diterima dan H8a, H8d, H8e ditolak).

Tabel 8. Hasil Analisis Uji Mediasi

\begin{tabular}{|c|c|c|c|c|}
\hline & Path Coefficient & T Statistics & P Values & Verification \\
\hline \multicolumn{5}{|c|}{ Mediator: Kesadaran Merek } \\
\hline $\mathrm{FH}->\mathrm{KM}$ & 0,272 & $3,701^{*}$ & $0,000^{*}$ & \multirow{3}{*}{$\begin{array}{c}\text { Mediasi } \\
\text { Komplementer }\end{array}$} \\
\hline KM -> LM & 0,251 & $3,441^{*}$ & $0,001^{*}$ & \\
\hline $\mathrm{FH}->\mathrm{LM}$ & 0,146 & $2,175^{*}$ & $0,030^{*}$ & \\
\hline FIKL $>\mathrm{KM}$ & 0,401 & $5,423^{*}$ & $0,000^{*}$ & \multirow{3}{*}{$\begin{array}{l}\text { Mediasi Tidak } \\
\text { Langsung }\end{array}$} \\
\hline KM -> LM & 0,251 & $3,441^{*}$ & $0,001^{*}$ & \\
\hline FIKL $>$ LM & 0,085 & 1,369 & 0,171 & \\
\hline FINT $->$ KM & 0,040 & 0,594 & 0,553 & \multirow{3}{*}{$\begin{array}{l}\text { Secara Langsung } \\
\text { (Non Mediasi) }\end{array}$} \\
\hline KM $->$ LM & 0,251 & $3,441^{*}$ & $0,001^{*}$ & \\
\hline FINT $->$ LM & 0,113 & $1,709^{\star *}$ & $0,088^{\star \star}$ & \\
\hline FK $->$ KM & 0,138 & 1,598 & 0,110 & \multirow{3}{*}{$\begin{array}{l}\text { Tidak Ada Efek } \\
\text { Mediasi }\end{array}$} \\
\hline KM $->$ LM & 0,251 & $3,441^{*}$ & $0,001^{*}$ & \\
\hline FK $->$ LM & 0,090 & 1,092 & 0,275 & \\
\hline $\mathrm{FT} \rightarrow \mathrm{KM}$ & 0,113 & $2,056^{*}$ & $0,040^{*}$ & \multirow{3}{*}{$\begin{array}{l}\text { Mediasi Tidak } \\
\text { Langsung }\end{array}$} \\
\hline KM $->$ LM & 0,251 & $3,441^{*}$ & $0,001^{*}$ & \\
\hline FT $->$ LM & 0,047 & 0,878 & 0,380 & \\
\hline \multicolumn{5}{|c|}{ Mediator: Citra Merek } \\
\hline $\mathrm{FH}->\mathrm{CM}$ & 0,088 & 1,122 & 0,262 & \multirow{3}{*}{$\begin{array}{l}\text { Secara Langsung } \\
\text { (Non Mediasi) }\end{array}$} \\
\hline CM -> LM & 0,228 & $3,425^{*}$ & $0,001^{*}$ & \\
\hline $\mathrm{FH}->\mathrm{LM}$ & 0,146 & $2,175^{\star}$ & $0,030^{*}$ & \\
\hline FIKL $>C M$ & 0,138 & 1,642 & 0,101 & \multirow{3}{*}{$\begin{array}{c}\text { Tidak Ada Efek } \\
\text { Mediasi }\end{array}$} \\
\hline CM $->$ LM & 0,228 & $3,425^{*}$ & $0,001^{*}$ & \\
\hline FIKL $->$ LM & 0,085 & 1,369 & 0,171 & \\
\hline FINT $->$ CM & 0,174 & $2,494^{*}$ & $0,013^{*}$ & \multirow{3}{*}{$\begin{array}{c}\text { Mediasi } \\
\text { Komplementer }\end{array}$} \\
\hline CM -> LM & 0,228 & $3,425^{*}$ & $0,001^{*}$ & \\
\hline FINT $->$ LM & 0,113 & $1,709^{\star *}$ & $0,088^{* *}$ & \\
\hline $\mathrm{FK}->\mathrm{CM}$ & 0,135 & 1,472 & 0,141 & \multirow{3}{*}{$\begin{array}{l}\text { Tidak Ada Efek } \\
\text { Mediasi }\end{array}$} \\
\hline CM $->$ LM & 0,228 & $3,425^{*}$ & $0,001^{*}$ & \\
\hline FK $->$ LM & 0,090 & 1,092 & 0,275 & \\
\hline FT $->\mathrm{CM}$ & 0,104 & $2,056^{*}$ & $0,040^{*}$ & \multirow{3}{*}{$\begin{array}{l}\text { Mediasi Tidak } \\
\text { Langsung }\end{array}$} \\
\hline CM $->$ LM & 0,228 & $3,425^{*}$ & $0,001^{*}$ & \\
\hline FT $->$ LM & 0,047 & 0,878 & 0,380 & \\
\hline
\end{tabular}

Keterangan: $t$-statistik $\geq 1,96^{*} \geq 1,65^{\star *}$ signifikan $\quad \alpha=0,05^{*} 0,10^{* *}$ signifikan

Uji Efek mediasi menggunakan ketentuan Zhao et al., (2010), ditemukan hasil pada Tabel 8. sebagai berikut: $\mathrm{H7a}$, H8b diterima dengan Mediasi Komplementer; H7b, dab H8a ditolak dengan hubungan Secara 
Langsung (Non Mediasi); H7c, H7d, dan H8c diterima dengan Mediasi Tidak Langsung; H7e, H8d, dan H8e ditolak Tidak Ada Efek Mediasi.

\section{PEMBAHASAN}

Aktivitas pemasaran media sosial pada faktor hiburan, dan faktor interaksi memiliki pengaruh terhadap loyalitas merek. Pernyataan tersebut didukung oleh penelitian sebelumnya yang menyatakan selalu merespon tanggapan-tanggapan dari konsumennya, dengan begitu akan terbangun keterikatan antara perusahaan dengan konsumennya (Fadli, 2018). Sedangkan, aktivitas pemasaran media sosial pada faktor trendiness, faktor iklan, dan faktor kustomisasi tidak memiliki pengaruh terhadap loyalitas merek Scarlett di Instagram. Informasi seperti harga, produk apa saja yang dijual, fungsi produk, terdaftar BPOM, pemilik merek tersebut, bahan baku, review, reseller, konten iklan yang mengikuti zaman cenderung sama dengan akun Instagram merek kosmetik lain. Konsumen mendapatkan penawaran yang sama dan sejenis dengan merek lain. Adanya iklan yang tersebar di media sosial membuat konsumen lebih konsumtif dan timbul rasa penasaran untuk mencoba produk baru yang tampil di iklan instagram. Sesuai dengan penelitian Fitri dan Asthari (2018) yang menyatakan bahwa iklan kecantikan di media sosial instagram mempermudah konsumen untuk mendapatkan banyaknya informasi mengenai suatu produk kecantikan sehingga rasa keinginan untuk melihat, mempunyai, dan membeli produk kecantikan yang telah di iklankan semakin besar pada konsumen.

Perusahaan dapat meningkatkan loyalitas merek tanpa mediasi perusahaan dengan fokus aktivitas pemasaran media sosial terutama faktor hiburan dan faktor interaksi. Perusahaan dapat menampilkan konten secara rutin, menarik, konten yang menyenangkan, konten yang dapat menarik interaksi konsumen untuk ikut andil, mengadakan event secara online. Konten tersebut akan menstimulus ingatan konsumen pada merek Scarlett. Selain itu, perusahaan juga dapat melakukan pemasaran secara tidak langsung dari konsumen yang tertarik untuk ikut andil.

Hasil penelitian menunjukkan bahwa aktivitas pemasaran media sosial pada faktor hiburan, faktor trendiness, dan faktor iklan memiliki pengaruh terhadap loyalitas merek dengan kesadaran merek sebagai mediasi. Sesuai dengan peneliti sebelumnya yang menyatakan bahwa kesadaran merek terdiri dari empat tingkatan: pengenalan merek, ingat merek, merek top of the mind dan merek dominan (Aaker, 1996: 10-16 dikutip pada Bilgin, 2018). Sesuai dengan penelitian Hidajat, dan Keni (2019); Ismail (2017) yang menemukan bahwa kesadaran merek terbukti dapat memprediksi secara positif variabel brand loyalty sebagai mediasi aktivitas pemasaran media sosial sehingga dapat dinyatakan. Sedangkan, kesadaran merek tidak memediasi aktivitas pemasaran media sosial pada faktor interaksi, dan faktor kustomisasi terhadap loyalitas merek di Instagram. Hal tersebut dikarenakan interaksi baru dapat dilakukan jika konsumen telah mengetahui akun instagram Scarlett, kemudian 
perusahaan Scarlett menampilkan informasi merek yang sama dalam jangka panjang yang cenderung sama secara berkali-kali dan hanya dapat di akses oleh konsumen yang sudah mengetahui akun instagram merek Scarlett sehingga kedua faktor tersebut tidak dapat mempengaruhi kesadaran merek, dan tidak dapat berfungsi sebagai mediasi antar aktivitas pemasaran media sosial terhadap loyalitas merek di Instagram. Didukung dengan penelitian Santoso et al., (2017) yang menyatakan bahwa like dan komentar adalah fitur untuk melihat respon yang ditunjukkan follower dalam mengukur interaksi pada sosial media dimana menunjukkan bahwa interaksi dilakukan oleh konsumen yang telah mengetahui akun instagram suatu merek.

Kesadaran merek sebagai mediator untuk meningkatkan loyalitas merek konsumen baru yang belum pernah mengetahui produk merek Scarlett. Perusahaan perlu fokus pada aktivitas pemasaran media sosial terutama faktor hiburan, faktor iklan, dan faktor trendiness. Perusahaan dapat menyajikan konten yang menarik, namun dengan iklan menghibur, menyenangkan dalam waktu rutin yang dapat membuat calon konsumen penasaran, dan menampilkan iklan yang menghadirkan informasi seputar produk dan merek. Perusahaan Scarlett sebaiknya semakin aktif dalam melakukan penelitian untuk menyesuaikan perkembangan zaman sehingga perusahaan Scarlett dapat selalu berinovasi dan mengaktualisasikan tampilan pada akun instagram.

Hasil penelitian juga menyatakan aktivitas pemasaran media sosial faktor interaksi, dan faktor trendiness terhadap loyalitas merek dengan citra merek sebagai mediasi di media sosial (instagram). Hal tersebut sesuai dengan penelitian (Musa et al., 2016; Schiffman et al., 2010) yang menyatakan Media sosial dapat memiliki dampak dramatis pada reputasi merek, perusahaan dapat memanfaatkan media sosial untuk meningkatkan kebajikan dan kepercayaan mereka sebagai konsumen yang lebih memilih untuk membeli merek yang sama secara konsisten dalam kategori produk atau layanan tertentu. Aktivitas pemasaran media sosial pada faktor hiburan, faktor iklan, dan faktor kustomisasi terhadap loyalitas merek dengan menggunakan citra merek sebagai mediator tidak berpengaruh di Instagram. Foto produk, harga produk, segala informasi yang di butuhkan konsumen, serta menampilkan iklan secara rutin, dan mengikuti perkembangan zaman disediakan. Namun, hal tersebut tidak mempengaruhi citra merek dikarenakan aspek tersebut bukanlah aspek yang dibutuhkan konsumen untuk menilai reputasi atau citra suatu merek. Sesuai dengan penelitian yang menyatakan kesadaran merek adalah cerminan dari indikator konkret suatu merek seperti nama, tanda, simbol, dan slogan, sedangkan citra merek adalah posisi merek di benak konsumen di luar tanda-tanda ini (Bilgin, 2018).

Selanjutnya, meningkatkan loyalitas merek konsumen lama dengan menggunakan citra merek sebagai mediator. Perusahaan Scarlett dapat melakukan aktivitas pemasaran media sosial terutama pada faktor interaksi dan faktor trendiness. Perusahaan dapat meningkatkan interaksi 
pada konsumen melalui kolom komentar, direct massage, dan features meminta tanggapan konsumen melalui story instagram, menampilkan konten menarik, mengajak konsumen untuk aktif memberi komentar dengan kuis ringan, memberikan hadiah rutin (bulanan/akhir tahun), giveaway, menyajikan konten teraktual, menampilkan konten yang berhubungan dengan fenomena yang sedang banyak diperbincangkan, pembaruan tampilan akun Instagram Scarlett secara berkala, menampilkan akun Instagram konsumen yang merespon akan membuat konsumen merasa diakui, dan diperhatikan oleh perusahaan. Hal tersebut akan membuat konsumen menjadi merasa nyaman, diakui, dan semakin setia pada merek Scarlett. Konsumen yang merasa nyaman tidak akan menahan diri untuk mencoba varian lain dari produk merek Scarlett.

Penelitian ini memiliki beberapa keterbatasan yaitu kuesioner yang disebarkan kepada responden hanya secara online, penelitian ini tidak acak yaitu purposive sampling dengan ukuran terbatas, penelitian ini hanya menganalisis pengaruh dari aktivitas pemasaran media sosial (Instagram), penelitian tidak melakukan perbandingan dengan pengaruh cara marketing lain seperti endorser, system reseller, system dropshipper, dan lainnya. Kemudian keterbatasan lain terletak pada sampel perempuan yang memiliki jumlah lebih banyak daripada laki-laki.

\section{KESIMPULAN}

Kesimpulan penelitian kali ini yaitu menggunakan data primer. Data didapatkan dari penyebaran kuesioner secara online menggunakan Google Forms kemudian link kuesioner disebarkan melalui media sosial seperti Line, Instagram, Whatsapp, Twitter, dan Facebook dari. Data yang diolah sebanyak 238 dari responden yang memenuhi kriteria yaitu pernah membeli produk Scarlett setidaknya 2 kali dalam 1 tahun terakhir, mengikuti akun instagram Scarlett (@Scarlett_Whitening), dan berusia minimal 17 tahun. Analisis Data pada penelitian ini menggunakan Structural Equation Modeling (SEM), dengan bantuan software Partial Least Square (PLS) dan melakukan efek uji mediasi menggunakan ketentuan Zhao et al., (2010).

Hasil dari pengujian menemukan bahwa adanya pengaruh aktivitas pemasaran media sosial pada faktor hiburan, faktor trendiness, dan faktor iklan terhadap kesadaran merek (H1a, H1c, H1d diterima), sedangkan, faktor interaksi, dan kustomisas tidak berpengaruh terhadap kesadaran merek di media sosial (Instagram) (H1b, dan H1e ditolak). Selanjutnya, adanya pengaruh aktivitas pemasaran media sosial terutama pada faktor trendiness, dan faktor interaksi memiliki pengaruh terhadap citra merek Scarlett di Instagram (H2b, dan H2c diterima), sedangkan faktor hiburan, iklan, dan faktor kustomisasi tidak berpengaruh terhadap kesadaran merek di media sosial (Instagram) (H2a, H2d, dan H1e ditolak). Hubungan langsung aktivitas pemasaran media sosial terutama pada faktor hiburan dan faktor interaksi memiliki pengaruh terhadap loyalitas merek Scarlett di Instagram (H3a, dan H3b diterima). Sedangkan, faktor 
trendiness, faktor iklan, dan faktor kustomisasi) tidak berpengaruh terhadap loyalitas merek di media sosial (Instagram) (H3c, H3d, dan H3e ditolak). Berdasarkan penelitian juga ditemukan bahwa kesadaran merek memiliki pengaruh terhadap citra merek Scarlett di Instagram (H4 diterima). Selain itu, peneliti menemukan bahwa adanya pengaruh kesadaran merek dan citra merek terhadap loyalitas merek Scarlett di Instagram ( $\mathrm{H} 5$, dan $\mathrm{H} 6$ diterima). Kemudian dengan kesadaran merek memediasi aktivitas pemasaran media sosial terutama pada faktor hiburan, faktor iklan, dan faktor trendiness memiliki pengaruh terhadap loyalitas merek di Instagram ( $\mathrm{H} 7 \mathrm{a}, \mathrm{H} 7 \mathrm{c}$, dan $\mathrm{H} 7 \mathrm{~d}$ diterima), sedangkan faktor interaksi dan faktor kustomisasi tidak berpengaruh terhadap loyalitas merek dengan kesadaran merek sebagai mediasi di instagram (H7b dan $\mathrm{H} 7 \mathrm{e}$ ditolak). Pengaruh aktivitas pemasaran media sosial (interaksi, dan trendiness) terhadap loyalitas merek dengan citra merek sebagai mediasi di instagram memiliki pengaruh ( $\mathrm{H} 8 \mathrm{~b}$, dan $\mathrm{H} 8 \mathrm{c}$ diterima). sedangkan faktor hiburan, faktor iklan, dan faktor kustomisasi tidak berpengaruh terhadap loyalitas merek dengan citra merek sebagai mediasi di media sosial (instagram) (H8a, H8d, dan H8e ditolak). Berdasarkan kesimpulan yang ada pada dasarnya perusahaan Scarlett bisa mendapatkan loyalitas konsumen terhadap merek Scarlett baik dengan mediasi atau tanpa mediasi.

\section{DAFTAR PUSTAKA}

Almohaimmeed, Bader M. A. (2019). The Effects of Social Media Marketing Antecedents on Social Media Marketing, Brand Loyalty and Purchase Intention: A Customer Perspective. Journal of Business and Retail Management Research (JBRMR), Vol. 13(4): pp. 147-158.

Bilgin, Yusuf. (2018). The Effect Of Social Media Marketing Activities On Brand Awareness, Brand Image And Brand Loyalty. Business \& Management Studies: An International Journal BMIJ, Vol. 6(1): 128148.

Ceyhan, Ayben. (2019). The Impact of Perception Related Social Media Marketing Applications on Consumers' Brand Loyalty and Purchase Intention. Emerging Markets Journal, Vol. 9(1): 2158-8708.

Fadli, Rian. (2018). Pemanfaatan Media Sosial Instagram Akun @Vapormxpku Dalam Meningkatkan Promosi Penjualan. JOM Fisip, Vol. 5(2).

Fitri, Dwi., dan Asthari, Nurul. 2018. Fenomena Beauty Advertising Brand Kosmetik pada Minat Beli Konsumen (Studi Pada Tayangan Iklan Kecantikan Brand Kosmetik Wardah di Media Sosial Instagram pada Mahasiswi Universitas Malikussaleh). Jurnal Jurnalisme, Vol. 7 (2)

Ghozali, Imam., dan Latan, Hengky. (2015). Partial Least baderSquare Konsep Teknik dan Aplikasi Menggunakan Program SmartPLS 3.0 (2nd Edition). Semarang: Badan Penerbit Universitas Diponegoro. 
Huda, Larissa. (27 Januari 2020). Perubahan Gaya Hidup Dorong Industri Kosmetik. URL https://koran.tempo.co/read/ekonomi-danbisnis/449594/perubahan-gaya-hidup-dorong-industri-kosmetik

Hidajat, Stanly., dan Keni. 2019. Prediksi Social Media Marketingdan Brand Uniqueness Terhadap Brand Loyalty: Brand Consciousness Sebagai Variabel Mediasi. Jurnal Manajerial dan Kewirausahaan, Vol. (I)2, 325-334.

Instagram Scarlett. (20 Agustus 2020). Akun instagram resmi Scarlett. URL https://www.instagram.com/scarlett_whitening/?hl=en

Instagram Pixy. (20 Agustus 2020). Akun instagram resmi Pixy. URL https://www.instagram.com/pixycosmetics/?hl=en

Instagram Viva. (20 Agustus 2020). Akun instagram resmi Viva. URL https://www.instagram.com/viva.cosmetics/?hl=en

Instagram Emina. (20 Agustus 2020). Akun instagram resmi Emina. URL https://www.instagram.com/eminacosmetics/?hl=en

Instagram Wardah. (20 Agustus 2020). Akun instagram resmi Wardah. URL https://www.instagram.com/wardahbeauty/?hl=en

Ismail, Ahmed Rageh. (2017). The influence of perceived social media marketing activities on brand loyalty: The mediation effect of brand and value consciousness. Asia Pacific Journal of Marketing and Logistics, Vol.29(1), 129-144. https://doi.org/10.1108/APJML-102015-0154.

Munaf, Triawan. (2018). Bangkitnya Label Lokal Retas, Badan Ekonomi Kreatif, Vol.7: 4-7.

Musa, Haslinda., Azmia, Fadhlur Rahim., Rahima, Namirah Ab., Shibghatullaha, Abdul Samad., Othmana, Norfaridatul Akmaliah. (2016). Analyzing the Effectiveness of Social Media Marketing. Future Academy. The European Proceedings of Social and Behavioural Sciences, Ep SBS, elSSN 2357-1330.

Pratnyawan, Agung. (19 Juni 2019). Pengguna Instagram dan Facebook Indonesia Terbesar ke-4 di Dunia. URL https://www.suara.com/tekno/2019/06/19/133252/pengguna-

instagram-dan-facebook-indonesia-terbesar-ke-4-di-dunia?page=all

Santoso, Amanda P., Baihaqi, Imam., dan Persada, Satria F. (2017).

Pengaruh Konten Post Instagram terhadap Online Engagement:

Studi Kasus pada Lima Merek Pakaian Wanita. Jurnal Sains Dan Seni ITS, Vol. 6(1), ISSN: 2337-3520

Schiffman, L.G., \& Kanuk, L.L. (2010). Consumer Behaviour (10th ed). New Jersey, Pearson Prentice Hall.

Sehar, Rida., Ashraf, Sarfraz., dan Azam , Faisal. (2019). The Influence of Social Media's Marketing Efforts on Brand Equity and Consumer Response. The IUP Journal of Marketing Management, Vol. XVIII(2), 31-53.

Zhao, X., Lynch, JR, J. G., and Chen, Q. (2010). Reconsidering Baron and Kenny: Myths and Truths about Mediation Analysis. The Journal of Consumer Research, Vol.3(2) 